\title{
Portfolio Optimization of Equity Mutual Funds-Malaysian Case Study
}

\author{
Adem Kılıçman' and Jaisree Sivalingam² \\ ${ }^{1}$ Department of Mathematics and Institute for Mathematical Research, University Putra Malaysia, 43400 UPM, \\ Serdang, Selangor, Malaysia \\ ${ }^{2}$ Department of Mathematics, University Malaysia Terengganu, 21030 UMT, Kuala Terengganu, \\ Terengganu, Malaysia \\ Correspondence should be addressed to Adem Kılıçman, akilicman@putra.upm.edu.my
}

Received 29 June 2009; Revised 4 December 2009; Accepted 23 January 2010

Academic Editor: Adel Alimi

Copyright (๑) 2010 A. Kılıçman and J. Sivalingam. This is an open access article distributed under the Creative Commons Attribution License, which permits unrestricted use, distribution, and reproduction in any medium, provided the original work is properly cited.

\begin{abstract}
We focus on the equity mutual funds offered by three Malaysian banks, namely Public Bank Berhad, CIMB, and Malayan Banking Berhad. The equity mutual funds or equity trust is grouped into four clusters based on their characteristics and categorized as inferior, stable, good performing, and aggressive funds based on their return rates, variance and treynor index. Based on the cluster analysis, the return rates and variance of clusters are represented as triangular fuzzy numbers in order to reflect the uncertainty of financial market. To find the optimal asset allocation in each cluster we develop a hybrid model of optimization and fuzzy based on return rates, variance. This was done by maximizing the fuzzy return for a tolerable fuzzy risk and minimizing the fuzzy risk for a desirable fuzzy return separately at different confidence levels.
\end{abstract}

\section{Introduction}

The portfolio optimization is also known as a risk management, and how to obtain the optimal solution of portfolio allocation has atracted many researchers on portfolio decision-making in the recent years. Thus the objective for models, either the return model or the risk model, is to maximize the profit or to minimize the cost for portfolio selection based on mean-variance (MV) theorem that was proposed by Markowitz.

Nowadays, mutual funds have become an ideal form of investment for many people since they have the ability to separate risks to the smallest degree. Therefore, it is not surprising at all to have many banks offering equity mutual fund schemes since it is investors' preference. However, selecting the best equity mutual fund is a difficult process. In the selection process, investors normally analyze the past performance of funds in order to evaluate the future performance. But sometimes, this method cannot be used for prediction of the future performance of funds due to the high volatility of market environment that is there is no assurance past trends will continue.
Thus Ammar and Khalifa [1] introduced the formulation of fuzzy portfolio optimization problem as a convex quadratic programming approach and gave an acceptable solution to such problems. They determined how much money should be allocated to each investment so that the total expected return would be greater than or equal to some lowest fuzzy return or the total fuzzy variance less than or equal to some greatest fuzzy variance.

In a recent study, by Chen and Huang [2], the uncertainty of future return rates and risk was considered and presented in triangular fuzzy numbers in contrast with the previous research whereby return rates were of trapezoidal form. They solved the optimal asset allocation by fuzzy optimization. This portfolio selection model was developed by using the Ammar and Khalifa [1] model and applied to Taiwan's equity mutual fund.

The present paper therefore also focuses on equity mutual funds and proposes a basic portfolio selection model for three selected banks of Malaysia, where the future return rates and future risks are represented by also triangular fuzzy numbers. In this work we use the cluster analysis, and the equity funds are clustered into four groups and categorized 
based on the performance evaluation techniques by using rate of return, Treynor Index, and variance, respectively.

The aim of this study is also to help the investors by providing a more sensible basis for decision making since indefinite financial environment is taken into account. The uncertainty of future return rates and risks was considered and presented in triangular fuzzy numbers, where question of how much money to allocate for each investment asset is answered by employing fuzzy optimization in order to solve the optimal asset allocation; see [2] where the authors performed an empirical study to Taiwan Listed Equity Mutual Fund and analyzed the performance of equity mutual funds based on their rates of return, standard deviation, Treynor Index, and Turnover rate.

Thus in this study, we apply fuzzy optimization (see for details $[3,4]$ ) to the equity mutual funds which are offered by three different Malaysian Banks, namely, Public Bank Berhad, CIMB, and Malayan Banking Berhad. Only equity funds from these banks were selected since they provide higher returns compared to equity funds that are offered by other institutions. The performance of these funds will be investigated and the ideal portion of money to be invested in order to obtain optimal return rates with bearable risk or minimum risk and further a desirable return will also be determined. Thus the objectives of this research can be summarized as follows.

(1) To investigate the performance of mutual funds in Malaysia by using cluster analysis and fuzzy method.

(2) To determine the best allocation of money to equity mutual funds in order to gain optimal return rates with tolerable investment risk or minimize investment risk.

In the progress of study we use the following terminologies.

(1) Net Asset Value. Net asset value is the current market value of all the fund's assets, minus liabilities, divided by the outstanding number of shares; see [5].

(2) Rate of Return. Rate of return is calculated based on net asset value as follows

$$
R_{i}=\frac{\mathrm{NAV}_{i 1}-\mathrm{NAV}_{i 0}}{\mathrm{NAV}_{\text {io }}} \times 100 \%,
$$

where, $i$ represents the number of funds, $R_{i}$ represents rate of return of portfolio $i$ (in percentage), $\mathrm{NAV}_{\mathrm{i} 1}$ represents net asset value of funds at current evaluation period, $\mathrm{NAV}_{\mathrm{i} 0}$ represents net asset value of funds at previous evaluation period.

(3) Treynor Index. The measure of a portfolio's excess return per unit of risk calculated by

$$
T_{i}=\frac{\bar{R}_{i}-\bar{R}_{f}}{\beta_{i}},
$$

where, $i$ represents number of funds, $T_{i}$ represents Treynor's portfolio performance measure of portfolio $i, \beta_{i}$ represents beta of portfolio $i$ over the evaluation period, $\bar{R}_{i}$ represents average holding period returns on the portfolio $i$ over the evaluation period, $\bar{R}_{f}$ represents average risk-free return over the evaluation period.

Note that Treynor index is similar to Sharpe's ratio (see [6]) but it measures excess return of portfolio per unit of systematic risk whereas Sharpe's ratio measures excess return of portfolio per unit of total risk.

(4) Variance. We have

$$
\sigma_{i}^{2}=\frac{\sum_{j=1}^{n}\left(R_{i j}-\bar{R}\right)^{2}}{n-1},
$$

where, $\sigma^{2}{ }_{i}=$ variance for portfolio $i, R_{i j}$ represents rate of return of portfolio $i$ on the $j$ th day, $\bar{R}$ represents average return rates of $n$ days,

According to Markowitz [7, 8] higher levels of return are accompanied by higher risk. He suggested the mean-variance methodology to solve the portfolio problem whereby the return is maximized for the same level of risk or risk is minimized for a given return. In this model, return is measured as mean and risk quantified as variance; however, complicated calculation is required in Markowitz model $[7,8]$.

\section{Methodology}

The primary objective of this research is to optimize a portfolio of equity mutual funds. Therefore, we first have to choose the right funds based on its performance. Once, a desirable portfolio of equity mutual funds is selected, we decide how much money should be allocated to each investment. To simplify matters, this chapter is divided into two sections whereby the first section is devoted to portfolio selection and the second is about portfolio optimization.

2.1. Research Scope. The data for this research consist of 38 equity funds both local and global, which are distributed and managed by CIMB, Public Mutual Berhad, and Malayan Banking Berhad. Although, the total number of equity funds offered by these banks are 58 in total, only 38 funds were selected for the purpose of this research. The other funds were eliminated due to incomplete data. In fact it might also be an open problem to study case for another 20 funds under incomplete data. Although, the time period of study is one year that is 365 days, the data available was for 216 days only minus weekends and public holidays because the counters were closed on these days. There were also few days where the reading was not taken due to certain problems. Other data's regarding the risk-free rate were taken from the website Central Bank of Malaysia (Bank Negara Malaysia) http://www.bnm.gov.my.

2.2. Portfolio Selection. For the selection of portfolio of funds we use cluster analysis. Thus the objective of cluster analysis is to separate the characteristics of funds into groups to help investors in selection process which groups of equity funds 
to invest in. The cluster analysis is done in two parts. In the first part, funds are clustered using Ward's method with correlation as similarity measure whereas in the second part, the number of clusters is determined.

2.3. Performance Evaluation Techniques. Once the results of the cluster analysis obtained then each cluster is analysed based on the three performance evaluation techniques to categorize the cluster of funds with its performance level. For the evaluation techniques the rate of return, Treynor index, and variance were used. Actually, the Treynor index is only used to differentiate the evaluation of funds performance and was not adapted in the optimization model. Variance, on the other hand, was a measure of risk and higher risk might give higher returns.

2.4. Portfolio Optimization. The objective of portfolio optimization is to determine the best allocation of money in the portfolio of mutual funds. This can be done by either maximizing the return for a given risk or minimizing risk for a given return. The rate of return and the variance were represented as fuzzy numbers in order to reflect the uncertainty at the evaluation stage. Further, the optimization method for fuzzy models is developed based on Ammar and Khalifa model [1]. In this study, given the past return of each cluster, we approximate values such as future expected return and future risk. As in Chen and Huang [2], the fuzzy return rates are denoted as a triangular fuzzy numbers, $\widetilde{R}=(l, m, n)$, whose membership function is as follows:

$$
\mu_{\widetilde{R}}(t)= \begin{cases}\frac{(t-l)}{(m-l)}, & l \leq t \leq m, \\ 1, & t=0, \\ \frac{(n-t)}{(n-m)}, & m \leq t \leq n, \\ 0, & t<1 \text { or } t>n .\end{cases}
$$

The $\alpha$-level confidence of $\widetilde{R}$ in terms of interval values corresponding to the triangular fuzzy numbers $\widetilde{R}=(l, m, n)$, as follows:

$$
\begin{aligned}
\widetilde{R}_{\alpha} & =\left[R_{\alpha}^{-}, R_{\alpha}^{+}\right] \\
& =[(m-l) \alpha+l, n-(n-m) \alpha] \quad \forall \alpha \in[0,1],
\end{aligned}
$$

where $((m-l) \alpha)$ and $(n-(n-m) \alpha)$ are the lower and upper bounds of the $\alpha$-level confidence. Similarly, fuzzy variance is denoted by $\tilde{\sigma}=\left[l_{*}, m_{*}, n_{*}\right]$ with the membership function:

$$
\mu_{\widetilde{\sigma}^{2}}(t)=t>n_{*} \begin{cases}\frac{\left(t-l_{*}\right)}{\left(m_{*}-l_{*}\right)}, & l_{*} \leq t \leq m_{*}, \\ 1, & t=m_{*}, \\ \frac{\left(n_{*}-t\right)}{\left(n_{*}-m_{*}\right)}, & m_{*} \leq t \leq n_{*}, \\ 0, & t<l_{*} \text { or } t>n_{*} .\end{cases}
$$

The $\alpha$-level confidence of $\tilde{\sigma}$ in terms of interval values corresponding to the triangular fuzzy number $\tilde{\sigma}^{2}=\left[l_{*}, m_{*}, n_{*}\right]$ is

$$
\begin{aligned}
\tilde{\sigma}_{\alpha}^{2} & =\left[\sigma_{\alpha}^{2-}, \sigma_{\alpha}^{2+}\right] \\
& =\left[\left(m_{*}-l_{*}\right) \alpha+l_{*}, n_{*}-\left(n_{*}-m_{*}\right) \alpha\right] \quad \forall \alpha \in[0,1],
\end{aligned}
$$

where the lower and upper bounds of the $\alpha$-level confidence can also be obtained. The portfolio optimization problem can be developed in two ways by using (5) and (7). Firstly, to maximize the expected return subject to a given risk. $M$ is the crisp maximum of fuzzy variance and $x_{i}$ is the investment proportion in cluster $i$

$$
\begin{aligned}
\text { Maximize : } & \widetilde{Z}_{\widetilde{R}}^{\alpha}(x)=\sum_{i=1}^{N}\left[\left(\widetilde{R}_{i}^{-}\right)_{\alpha},\left(\widetilde{R}_{i}^{+}\right)_{\alpha}\right] x_{i}, \\
\text { Subject to : } & \sum_{i=1}^{N}\left[\left(\sigma_{i}^{-}\right)_{\alpha}^{2},\left(\sigma_{i}^{+}\right)_{\alpha}^{2}\right] x_{i}^{2} \leq M, \\
& \sum_{i=1}^{N} x_{i}=1, \quad \text { where } x_{i} \geq 0, i=1, \ldots, N .
\end{aligned}
$$

Secondly, to minimize future risk subject to an expected return. $L$ is the crisp minimum of fuzzy return and $x_{i}$ is the investment proportion in cluster $i$

$$
\begin{aligned}
\text { Minimize : } & \tilde{Z}_{\widetilde{\sigma}}^{\alpha}(x)=\sum_{i=1}^{N}\left[\left(\sigma_{i}^{-}\right)_{\alpha,}^{2}\left(\sigma_{i}^{+}\right)_{\alpha}^{2}\right] x_{i}^{2}, \\
\text { Subject to : } & \sum_{i=1}^{N}\left[\left(\widetilde{R}_{i}^{-}\right)_{\alpha,}\left(\widetilde{R}_{i}^{+}\right)_{\alpha}\right] x_{i} \geq L, \\
& \sum_{i=1}^{N} x_{i}=1, \quad \text { where } x_{i} \geq 0, i=1, \ldots, N .
\end{aligned}
$$

Both of the problems could be solved by satisfying the KuhnTucker conditions based on the lower and upper bounds, separately, at different a-level confidences. The optimal solutions at $\alpha$ level will be in $\left[Z_{\alpha}^{-}(x), Z_{\alpha}^{+}(x)\right]=\widetilde{Z}_{\alpha}(x)$; see [2]. In conclusion, investors can choose either one of these model based on their preferences to solve the optimization problem.

\section{Results and Discussion}

This section is divided into three subsections based on the three methods that is cluster analysis, fuzzy method, and optimization. Each section is devoted to the gained results, their interpretation as well as discussion.

3.1. Cluster Analysis. The cluster analysis is performed by using MINITAB 14.0 Software. The input needed for the cluster analysis is the daily rate of return for all the funds. The cluster analysis is done by following two stages. Firstly, Ward's method is used to separate the funds into groups. 
TABLe 1: Summary of Cluster Analysis Results.

\begin{tabular}{lcccc}
\hline $\begin{array}{l}\text { Performance } \\
\text { evaluation } \\
\text { techniques }\end{array}$ & Cluster 1 & Cluster 2 & Cluster 3 & Cluster 4 \\
\hline Rate of return & 0.075 & 0.113 & 0.136 & 0.064 \\
Variance & 1.057 & 1.664 & 23.569 & 1.312 \\
Treynor index & 0.123 & 0.087 & 0.094 & 0.039 \\
Category & Stable & Good performing & Aggressive & Inferior \\
\hline
\end{tabular}

Secondly, $K$-means of nonhierachical method is used to determine the number of clusters. The number of cluster is set to be four $(k=4)$ because dividing it into three clusters would make the funds with different characteristics forced into a group. Thus, there would be less diversity between cluster two and four. Therefore, the suitable number of clusters is four. The cluster analysis results can be represented in a tree diagram or dendogram which might help in interpreting the clustering process.

Next, we categorize cluster based on their performance characteristics, namely, inferior funds, stable funds, good performing funds, and aggressive funds. The rate of return and variance of each cluster represented by its midpoint. The category of clusters is displayed in Table 1.

By looking at Table 1 it is observed that; The funds in Cluster 1 are categorized as stable since they have a rather standard return. It is the second lowest while Treynor Index is the highest whereas the variance the lowest which indicates a lower risk. Thus, we categorized Cluster 1 as stable.

Cluster 2 has high returns and low variance which shows low risk for a good return. Its Treynor index is the highest indicating that it is well diversified.

Cluster 3 has the highest return and highest variance which proves that higher return does come with higher risk. The Treynor index is in the second highest position which indicates that the systematic risk is small.

Cluster 4 has the lowest return but its variance is in the second lowest position instead of being the lowest since lowest return rate should have lowest risk. Thus, this cluster has inferior performance even though its Treynor index is higher than that of Cluster 1.

From the result of cluster analysis, investing in Cluster 2 and Cluster 3 would lead to higher profit compared to investing in the other clusters. Thus, investors are highly recommended to invest in these two clusters since expected return and the risk are two fundamental factors to consider. Thus the investors can select which funds to invest in from these clusters to form their portfolio.

3.2. Fuzzy Method. Since, the financial market is highly volatile and thus, the return rate and risks of investing in cluster 2 and cluster 3 most probably would not be the same as calculated in the table. In order to reflect this uncertainty of financial market we use triangular fuzzy numbers instead of a crisp representation to represent the future return rates and risks. Hence, the spread of each side of the triangle fuzzy number is a set as the minimum and maximum value of each variable (return rate and risk). Their values are given in Table 2.

\subsubsection{Representation of Cluster 2 and Cluster 3 as Triangular} Fuzzy Numbers. Return rates of Cluster 2 are denoted as a triangular fuzzy number, $\widetilde{R}_{2}=(0.035,0.128,0.191)$. The values of $l=0.035, m=0.113$ and $n=0.191$ are taken from the Table 2 and are substituted into (4) and its membership function is as follows:

$$
\mu_{\widetilde{R}_{2}}(t)= \begin{cases}t-(0.035) / 0.078, & 0.035 \leq t \leq 0.113 \\ 1, & t=0.113 \\ \frac{(0.191-t)}{0.078}, & 0.113 \leq t \leq 0.191 \\ 0, & t<0.035 \text { or } t>0.191\end{cases}
$$

The $\alpha$-level confidence of $\widetilde{R}$ in terms of interval values corresponding to the triangular fuzzy number, $\widetilde{R}_{2}=$ $(0.035,0.113,0.191)$, is given by

$$
\begin{aligned}
\widetilde{R}_{\alpha} & =\left[R_{\alpha}^{-}, R_{\alpha}^{+}\right] \\
& =[0.078 \alpha+0.035,0.191-0.078 \alpha] \quad \forall \alpha \in[0,1] .
\end{aligned}
$$

This is found by substituting the values of $\widetilde{R}_{2}$ in (5) where the lower and upper bounds of the $\alpha$-level confidence are obtained by substituting the values of $\alpha$.

Next, the variance of Cluster 2 is also represented as a triangular fuzzy number, $\tilde{\sigma}_{2}^{2}=[0.708,1.664,2.620]$. The values of $l=0.708, m=1.664$ and $n=2.620$ are taken from Table 2 and are substituted into (6) to obtain the following membership function:

$$
\mu_{\widetilde{\sigma}_{2}^{2}}(t)= \begin{cases}\frac{(t-0.708)}{0.956}, & 0.708 \leq t \leq 1.664, \\ 1, & t=1.664, \\ \frac{(2.620-t)}{0.956}, & 1.664 \leq t \leq 2.620, \\ 0, & t \leq 0.708 \text { or } t \leq 2.620 .\end{cases}
$$

The $\alpha$-level confidence of $\tilde{\sigma}^{2}$ in terms of interval values corresponding to the triangular fuzzy number, $\tilde{\sigma}_{2}^{2}=[0.708$, $1.664,2.620]$ is given by

$$
\begin{aligned}
\tilde{\sigma}_{\alpha}^{2} & =\left[{\sigma_{\alpha}^{2}}_{\alpha}^{-}, \sigma_{\alpha}^{2+}\right] \\
& =[0.956 \alpha+0.708,2.620-0.956 \alpha] \quad \forall \alpha \in[0,1],
\end{aligned}
$$

This is found by substituting the values $\tilde{\sigma}_{2}^{2}$ of in (7) where the lower and upper bounds of the $\alpha$-level confidence are obtained by substituting the values of $\alpha$. Similarly, the rate of return and variance of Cluster 3 are represented as triangular fuzzy numbers.

3.3. Optimization Model. The optimization problem is divided into two parts as follows. 
Table 2: Cluster Results Used in Fuzzy.

\begin{tabular}{|c|c|c|c|c|c|c|}
\hline \multirow{2}{*}{$\begin{array}{l}\text { Performance } \\
\text { Evaluation techniques }\end{array}$} & \multicolumn{3}{|c|}{ Cluster 2} & \multicolumn{3}{|c|}{ Cluster 3} \\
\hline & Midpoint (m) & $\operatorname{Min}(1)$ & $\operatorname{Max}(n)$ & Midpoint (m) & $\operatorname{Min}(1)$ & $\operatorname{Max}(n)$ \\
\hline Rate of return & 0.113 & 0.035 & 0.191 & 0.136 & 0.035 & 0.237 \\
\hline Variance & 1.664 & 0.708 & 2.620 & 23.569 & 2.223 & 44.915 \\
\hline
\end{tabular}

TABLE 3: Investment proportions with different levels of $\alpha$ for maximizing return.

\begin{tabular}{|c|c|c|c|c|}
\hline$\alpha$-level & $\begin{array}{l}\text { Upper bound of } \\
\text { variance }\end{array}$ & $\begin{array}{l}\text { Return intervals } \\
(\mathrm{Z})\end{array}$ & $\begin{array}{c}\text { Investment } \\
\mathrm{X} 2\end{array}$ & $\begin{array}{c}\text { Proportion } \\
\mathrm{X} 3 \\
\end{array}$ \\
\hline \multirow{5}{*}{$\alpha=0$} & $M \geq 44.915$ & {$[0.035,0.237]$} & {$[0,0]$} & {$[1,1]$} \\
\hline & $M=40$ & {$[0.035,0.237]$} & {$[0,0.056]$} & {$[0.944,1]$} \\
\hline & $M=35$ & {$[0.035,0.237]$} & {$[0,0.118]$} & {$[0.882,1]$} \\
\hline & $M=32$ & {$[0.035,0.237]$} & {$[0,0.5]$} & {$[0.5,1]$} \\
\hline & $M \leq 31$ & NFS & - & - \\
\hline \multirow{5}{*}{$\alpha=0.25$} & $M \geq 40$ & {$[0.0600,0.2120]$} & {$[0,0]$} & {$[1,1]$} \\
\hline & $M=35$ & {$[0.0597,0.2120]$} & {$[0,0.060]$} & {$[0.940,1]$} \\
\hline & $M=30$ & {$[0.0594,0.2120]$} & {$[0,0.130]$} & {$[0.870,1]$} \\
\hline & $M=15.1$ & {$[0.0581,0.2120]$} & {$[0,0.390]$} & {$[0.610,1]$} \\
\hline & $M \leq 15$ & NFS & - & - \\
\hline \multirow{4}{*}{$\alpha=0.5$} & $M \geq 35$ & {$[0.086,0.187]$} & {$[0,0]$} & {$[1,1]$} \\
\hline & $M=32$ & {$[0.086,0.187]$} & {$[0,0.033]$} & {$[0.967,1]$} \\
\hline & $M=25.1$ & {$[0.084,0.187]$} & {$[0,0.145]$} & {$[0.855,1]$} \\
\hline & $M \leq 25$ & NFS & - & - \\
\hline \multirow{4}{*}{$\alpha=0.75$} & $M \geq 32$ & {$[0.111,0.161]$} & {$[0,0]$} & {$[1,1]$} \\
\hline & $M=25$ & {$[0.110,0.161]$} & {$[0,0.070]$} & {$[0.930,1]$} \\
\hline & $M=22$ & {$[0.109,0.161]$} & {$[0,0.128]$} & {$[0.872,1]$} \\
\hline & $M \leq 21.9$ & NFS & - & - \\
\hline \multirow{6}{*}{$\alpha=1.0$} & $M \geq 25$ & 0.136 & 0 & 1 \\
\hline & $M=22$ & 0.135 & 0.034 & 0.966 \\
\hline & $M=10$ & 0.128 & 0.356 & 0.644 \\
\hline & $M=5$ & 0.123 & 0.565 & 0.435 \\
\hline & $M=3$ & 0.120 & 0.695 & 0.305 \\
\hline & $M \leq 2$ & NFS & - & - \\
\hline
\end{tabular}

3.3.1. Maximize Fuzzy Return Subject to a Given Fuzzy Variance. This is done to find the optimum investment proportion in Cluster 2 and Cluster 3 in order to gain the maximum fuzzy return for a given upper bound of fuzzy variance that an investor can tolerate. The optimization problem is developed as follows by using (11), (13), and $\widetilde{R}_{\alpha}$ and $\tilde{\sigma}_{\alpha}^{2}$ for cluster 3 where $\widetilde{R}_{\alpha}$ and $\tilde{\sigma}_{\alpha}^{2}$ for cluster 3 can be found by using (4), (5), (6) and (7) which is similar to that in Section 3.2.1:

$$
\begin{aligned}
\operatorname{Max} Z= & (0.078 \alpha+0.035,0.191-0.078 \alpha) x_{2} \\
& +(0.101 \alpha+0.035,0.237-0.101 \alpha) x_{3}
\end{aligned}
$$

Subject to

$$
\begin{aligned}
& (0.956 \alpha+0.708,2.620-0.956 \alpha) x_{2}^{2} \\
& \quad+(21.346 \alpha+2.223,44.915-21.346 \alpha) x_{3}^{2} \leq M \\
& x_{2}+x_{3}=1 \\
& x_{2}>0, \quad x_{3}>0 .
\end{aligned}
$$

By using (14), the problem is solved by applying the upper and lower bounds separately at different $\alpha$-level confidence that is, $\alpha=0,0.25,0.5,0.75$ and 1.0. For example for solving the problem with $\alpha=0$. If $M$ is the upper bound of variance that can be tolerated

$\operatorname{Max} Z=0.035 x_{2}+0.035 x_{3}$ (lower bound of return), s.t $2.62 x_{2}^{2}+44.915 x_{3}^{2} \leq M$ (upper bound of variance),

$$
\begin{aligned}
& x_{2}+x_{3}=1, \\
& x_{2}>0, x_{3}>0,
\end{aligned}
$$

$\operatorname{Max} Z=0.191 x_{2}+0.237 x_{3}$ (upper bound of return),

$$
\begin{aligned}
& \text { s.t } 0.708 x_{2}^{2}+2.223 x_{3}^{2} \leq M \text { (lower bound of variance), } \\
& \begin{array}{l}
x_{2}+x_{3}=1 \\
x_{2}>0, x_{3}>0
\end{array}
\end{aligned}
$$


TABLE 4: Investment proportions with different levels of $\alpha$ for minimizing risk.

\begin{tabular}{|c|c|c|c|c|}
\hline$\alpha$-level & $\begin{array}{l}\text { Minimum fuzzy } \\
\text { return }\end{array}$ & $\begin{array}{c}\text { Variance } \\
\text { intervals }(Z)\end{array}$ & $\begin{array}{c}\text { Investment } \\
\mathrm{X} 2 \\
\end{array}$ & $\begin{array}{c}\text { Proportion } \\
\text { X3 } \\
\end{array}$ \\
\hline \multirow{5}{*}{$\alpha=0.25$} & $L \geq 0.059$ & NFS & - & - \\
\hline & $L=0.058$ & {$[0.842,39.579]$} & {$[0,0.889]$} & {$[0.111,1]$} \\
\hline & $L=0.057$ & {$[0.842,17.855]$} & {$[0.333,0.889]$} & {$[0.111,0.667]$} \\
\hline & $L=0.056$ & {$[0.842,5.456]$} & {$[0.667,0.889]$} & {$[0.111,0.333]$} \\
\hline & $L \leq 0.055$ & {$[0.842,2.246]$} & {$[0.889,0.943]$} & {$[0.057,0.111]$} \\
\hline \multirow{6}{*}{$\alpha=0.5$} & $L \geq 0.083$ & NFS & - & - \\
\hline & $L=0.082$ & {$[1.086,34.242]$} & {$[0,0]$} & {$[1,1]$} \\
\hline & $L=0.081$ & {$[1.086,26.250]$} & {$[0.125,0.916]$} & {$[0.084,0.875]$} \\
\hline & $L=0.080$ & {$[1.086,19.395]$} & {$[0.250,0.916]$} & {$[0.084,0.750]$} \\
\hline & $L=0.079$ & {$[1.086,13.677]$} & {$[0.375,0.916]$} & {$[0.084,0.625]$} \\
\hline & $L \leq 0.074$ & {$[1.086,2.016]$} & {$[0.916,0.941]$} & {$[0.059,0.084]$} \\
\hline \multirow{6}{*}{$\alpha=0.75$} & $L \geq 0.133$ & NFS & - & - \\
\hline & $L=0.133$ & {$[1.425,6.510]$} & {$[0,0.418]$} & {$[0.582,1]$} \\
\hline & $L=0.13$ & {$[1.358,5.671]$} & {$[0.463,0.953]$} & {$[0.047,0.537]$} \\
\hline & $L=0.12$ & {$[1.358,3.458]$} & {$[0.612,0.953]$} & {$[0.047,0.388]$} \\
\hline & $L=0.11$ & {$[1.358,2.142]$} & {$[0.761,0.953]$} & {$[0.047,0.239]$} \\
\hline & $L \leq 0.1$ & {$[1.358,1.723]$} & {$[0.953,0.905]$} & {$[0.047,0.095]$} \\
\hline \multirow{6}{*}{$\alpha=1.0$} & $L \geq 0.137$ & NFS & - & - \\
\hline & $L=0.136$ & 23.569 & 0 & 1 \\
\hline & $L=0.135$ & 21.567 & 0.043 & 0.957 \\
\hline & $L=0.13$ & 12.989 & 0.261 & 0.739 \\
\hline & $L=0.12$ & 2.988 & 0.696 & 0.304 \\
\hline & $L \leq 0.1$ & 1.554 & 0.934 & 0.066 \\
\hline
\end{tabular}

The optimal solutions for different $\alpha$-level confidence can be obtained, similarly using the Lingo 11.0 Software. The results obtained areas shown in Table 3.

In Table 3, "NFS" means there is no solutions for the corresponding conditions. For $M$ greater than a certain variance for all the $\alpha$-levels, the optimal solutions remain the same, that is all investments are made in Cluster 3 only. For example, $M \geq 44.915$ shows that when $M$ equals to or greater than 44.915 , the return interval and investment proportions are the same. For $\alpha=0$, the fuzzy return interval is the same regardless of the risk because of the different proportions of investment in Clusters 2 and 3. This shows that we have managed to maintain the same level of return interval by making different investment proportions and hence succeeded in reducing the risk as well. Thus, if investors want to maximize fuzzy return with $\alpha=0$, they should invest in the proportion with the lowest risk since the return interval is the same.

On the other hand if investors want to maximize fuzzy return with $\alpha=0.25,0.5,0.75$, and 1.0 , they should choose the optimal investment proportion according to the return intervals they desire. However we note that the desirable return is accompanied with a fuzzy risk that should be tolerated with. Therefore, if investors want to desire a certain fuzzy return but they cannot tolerate its risk, then they should opt for return with tolerable risk and invest according to its optimal proportion. Besides that, the investment proportion in Cluster 3 is generally higher than that of
Cluster 2 because it has higher return. Thus it is also expected to invest more in Cluster 3 in order to to gain higher return. It is also observed that as $\alpha$-level increases, the return intervals becomes smaller.

\subsubsection{Minimize Fuzzy Risk Subject to a Given Fuzzy Return}

We have

$$
\begin{aligned}
\operatorname{Min} Z= & (0.956 \alpha+0.708,2.620-0.956 \alpha) x_{2}^{2} \\
& +(21.346 \alpha+2.223,44.915-21.346 \alpha) x_{3}^{2},
\end{aligned}
$$

Subject to

$$
\begin{aligned}
& (0.078 \alpha+0.035,0.191-0.078 \alpha) x_{2} \\
& \quad+(0.101 \alpha+0.035,0.237-0.101 \alpha) x_{3} \geq L \\
& x_{2}+x_{3}=1 \\
& x_{2}>0, x_{3}>0 .
\end{aligned}
$$

This optimization problem is solved at different $\alpha$ - level confidences and the results obtained are shown in Table 4.

In Table 4, "NFS" means that there is no feasible solution corresponding to the fuzzy return rates constraint. The results at $\alpha=0$ are not displayed although, there are feasible solutions because it is not significant. Thus, in this case, investors are not advised to choose the investment 
proportions at $\alpha=0$. It is observed that as $\alpha$-level increases, the variance intervals become smaller. As the variance becomes smaller (risk decreases), the investment proportion is higher in Cluster 2. The simple reason for that, the return of Cluster 2 is lower than Cluster 3, hence, its variance is also lower. Thus, if investors want to reduce risk, then they should invest mostly in Cluster 2.

\section{Conclusion and Suggestions}

In this paper, we used cluster analysis to aid investor in the portfolio selection. By using cluster analysis, we were able to categorize the funds in four groups according to their characteristics. This method is the fastest and a good way to categorize funds because it is not possible to classify a fund's performance unless we have compared it with the performance of all the other funds in the market. From the results of cluster analysis, it is observed that performance of funds in Cluster 2 and Cluster 3 dominates the other clusters. Thus, only the return rates and variance of these clusters are incorporated into the optimization model.

To reflect the uncertainty of financial environment, we denoted the return rates and risk in triangular fuzzy number instead of crisp representation. The optimal investment proportion is found using a hybrid of fuzzy and optimization. The solutions are found using the Lingo 11.0 Software. We used few different $\alpha$-cuts to demonstrate that the interval of variance and risks decreases as the value $\alpha$-cuts increases.

There is only a crisp figure for rates of return, risk, and investment proportion at $\alpha=1.0$ because the triangular fuzzy has reached its peak, thus only a crisp number will be obtained and not intervals. In general, the proportion of investment is higher in Cluster 3 compared to Cluster 2 for investors who pay more importance to return. On the other hand, investors who pay more attention to risk will invest more in Cluster 2. In this study, we found the optimal investment proportions by solving the optimization problem separately for the lower and upper bound.

\section{Acknowledgment}

The authors would like to express their sincere thanks to the referees for their very constructive comments and suggestions.

\section{References}

[1] E. Ammar and H. A. Khalifa, "Fuzzy portfolio optimizationa quadratic programming approach," Chaos, Solitons and Fractals, vol. 18, no. 5, pp. 1045-1054, 2003.

[2] L.-H. Chen and L. Huang, "Portfolio optimization of equity mutual funds with fuzzy return rates and risks," Expert Systems with Applications, vol. 36, no. 2, part 2, pp. 3720-3727, 2009.

[3] E. Vercher, J. D. Bermúdez, and J. V. Segura, "Fuzzy portfolio optimization under downside risk measures," Fuzzy Sets and Systems, vol. 158, no. 7, pp. 769-782, 2007.

[4] E. Vercher, "Portfolios with fuzzy returns: selection strategies based on semi-infinite programming," Journal of Computational and Applied Mathematics, vol. 217, no. 2, pp. 381-393, 2008.
[5] M. Mobius, Mutual Funds: An Introduction to the Core Concepts, John Wiley \& Sons, Singapore, 2007.

[6] W. F. Sharpe, "Mutual fund performance," Journal of Business, vol. 39, pp. 119-138, 1966.

[7] H. M. Markowitz, "Portfolio selection," The Journal of Finance, vol. 7, pp. 77-91, 1952.

[8] H. M. Markowitz, Portfolio Selection-Efficient Diversification of Investments, John Wiley \& Sons, New York, NY, USA, 1959. 

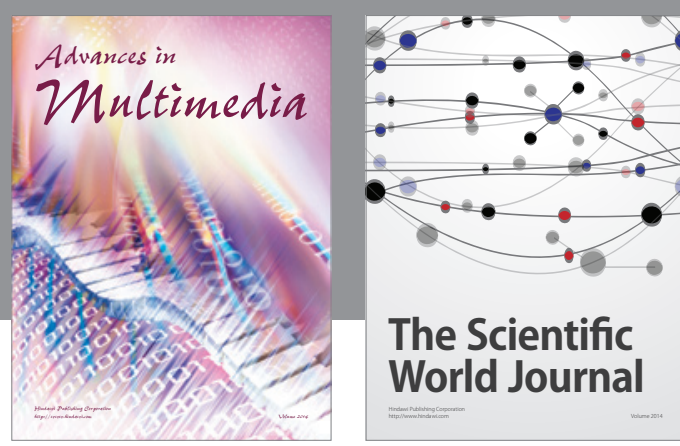

The Scientific World Journal
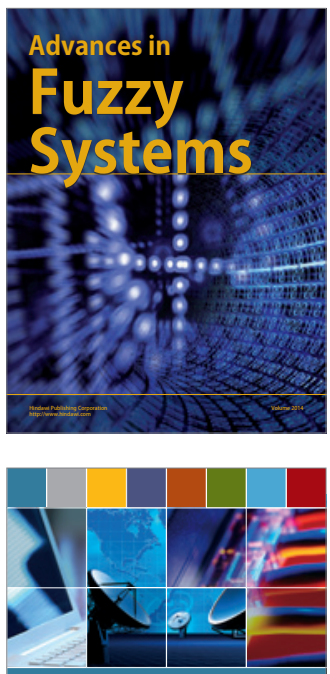

Computer Networks and Communications
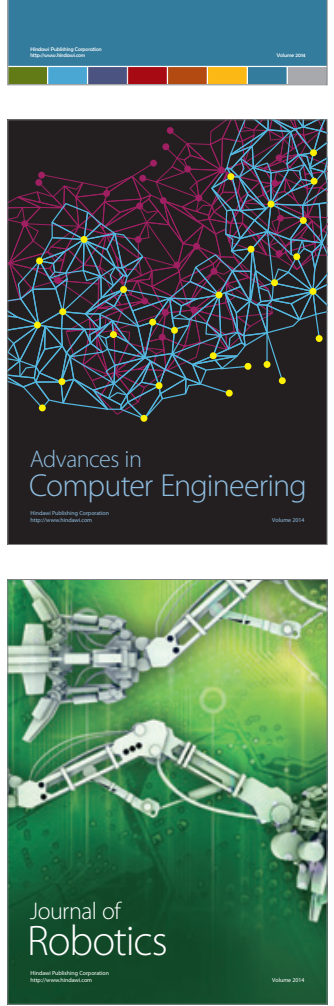
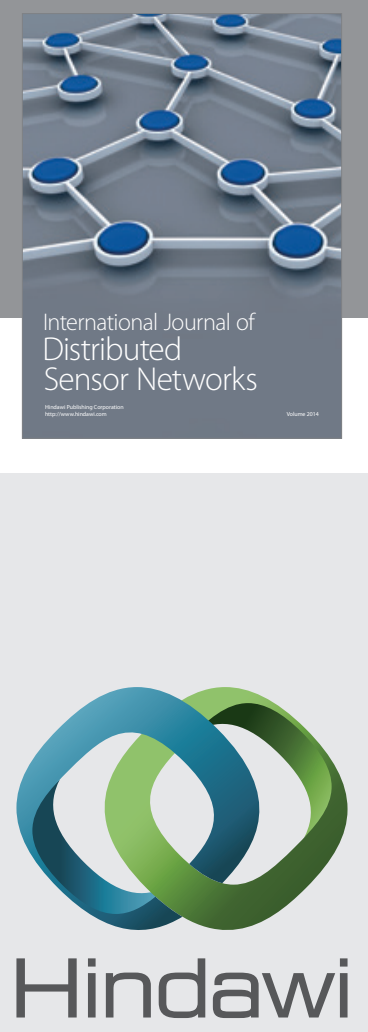

Submit your manuscripts at

http://www.hindawi.com
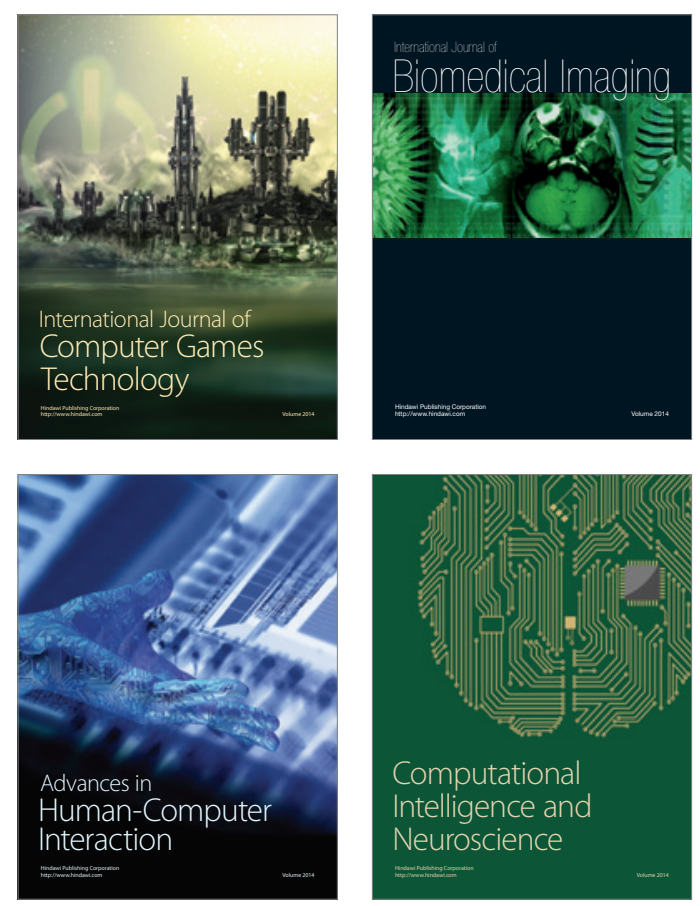
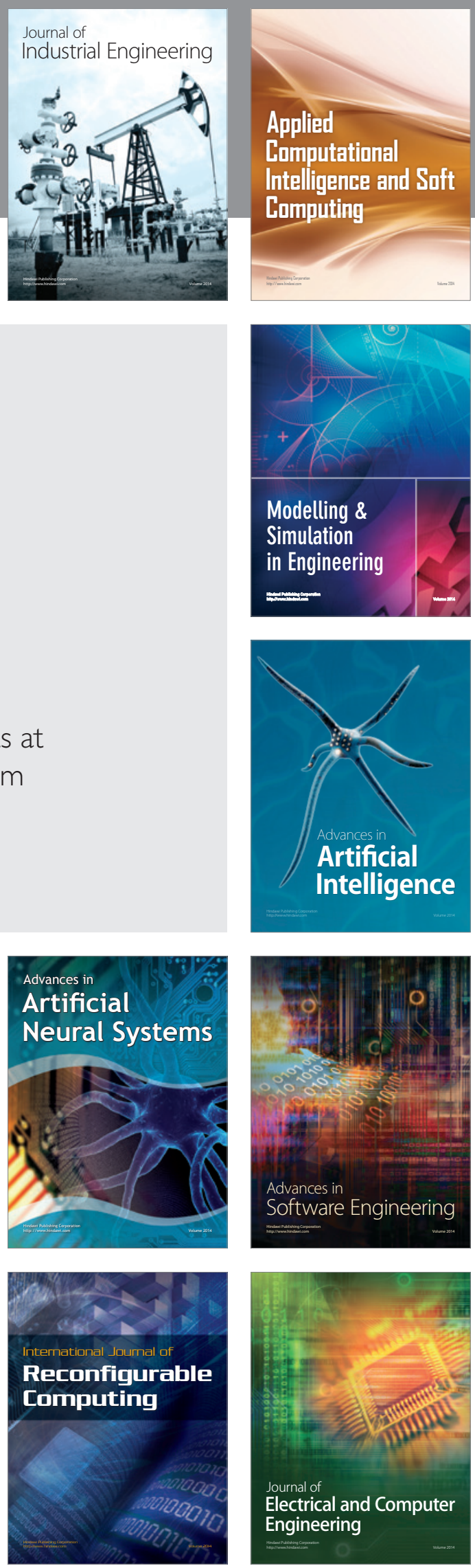